Please quote as: Weiß, F. \& Leimeister, J. M. (2014): Why can't I use my iPhone at work?: managing consumerization of IT at a multi-national organization. In: Journal of Information Technology Teaching Cases , Ausgabe/Number: 4, Erscheinungsjahr/Year: 2014. Seiten/Pages: 11-19. 


\title{
Why can't I use my iPhone at work?: managing consumerization of IT at a multi-national organization
}

\author{
Frank Weiß ${ }^{1}$, Jan Marco Leimeister ${ }^{2}$ \\ ${ }^{1}$ Information Systems, Kassel University, Kassel, Germany; \\ ${ }^{2}$ University of St. Gallen, Institute of Information Management (IWI HSG), St. Gallen, Switzerland. \\ E-mails: leimeister@uni-kassel.de; JanMarco.Leimeister@unisg.ch \\ Correspondence: \\ Frank Weiß, Information Systems, Kassel University, Pfannkuchstr 1, Kassel D-34121, Germany. \\ E-mail: weiss@wi-kassel.de
}

\begin{abstract}
As IT innovations in the last years emerged on the consumer market, employees are more experienced in the private than in the corporate use of innovative IT devices and applications. These employees, familiar with the benefits consumer products offer, expect those to be provided by their corporate IT. This trend, referred to as 'consumerization of IT', leads to more and more consumer innovations infiltrating companies. In particular, mobile consumer devices are currently spreading into companies, strongly pushed by top management, and create several challenges to Chief Information Officers (ClOs) around the globe: 'What IT costs are associated with the use of mobile consumer devices?', 'How will corporate use of mobile consumer devices affect IT management?', and 'How to introduce an IT service for corporate as well as personal mobile consumer devices?'. OMEGA Group, a multi-national company with 50,000 employees, wants to leverage the potential of mobile consumer devices for corporate purposes. Therefore, these questions have to be addressed and answered by its $\mathrm{ClO}$. The teaching case is designed to introduce the characteristics of consumerization and associated challenges for IT management. The case uses selected information systems methodologies and frameworks.
\end{abstract}

Journal of Information Technology Teaching Cases advance online publication, 1 October 2013; doi:10.1057/jittc.2013.3

Keywords: consumerization; mobile enterprise; IT governance; IT service management

\section{Introduction}

S even o'clock in the morning, the alarm clock application on John Smith's iPhone is ringing. ${ }^{1}$ He gets up, takes a shower and has a cup of coffee with Mary and the kids in the kitchen. To get the latest news, he opens his NY Times application on his iPhone and takes $5 \mathrm{~min}$ to screen the headlines. 'John, have you seen the pictures of Grandma's birthday?' asks his wife Mary. 'No, just upload them to Dropbox, I will flip through them on my iPhone this afternoon,' answers John. 'I never remember what time the train leaves in the morning,' says John and launches his community train application, 'Oh, I am late, sorry, need to hurry.' John packs his stuff and tries to catch the next underground train. Sitting in the train, reading the latest employee posts through the mobile application of an enterprise social network used within his company called 'Yammer' John thinks, 'The iPhone is a great tool, wherever I am I can stay current on the latest news, manage my private data, collaborate with others, stay in touch with our employees through social media, and these location based services are really fantastic. Why shouldn't this device be used for business purposes? It is more intuitive than my work BlackBerry. And why do I need to keep carrying around two devices?'

Mobile devices, smartphones and tablets from the consumer market (so-called 'mobile consumer devices') are spreading into companies around the world (Ingalsbe et al., 2011; Holtsnider and Jaffe, 2012). BlackBerrys, the legacy mobile enterprise devices, are still widely spread within companies but lose ground in employees' appreciation as devices based on consumer market operating systems, such as iOS and Android, gain more popularity (see Figure 1).

The trend that IT innovations (e.g., mobile devices and applications, so-called 'apps'), that originate in the consumer market, are infiltrating enterprises is called 'consumerization of IT' (Ingalsbe et al., 2011; Holtsnider and Jaffe, 2012). This 


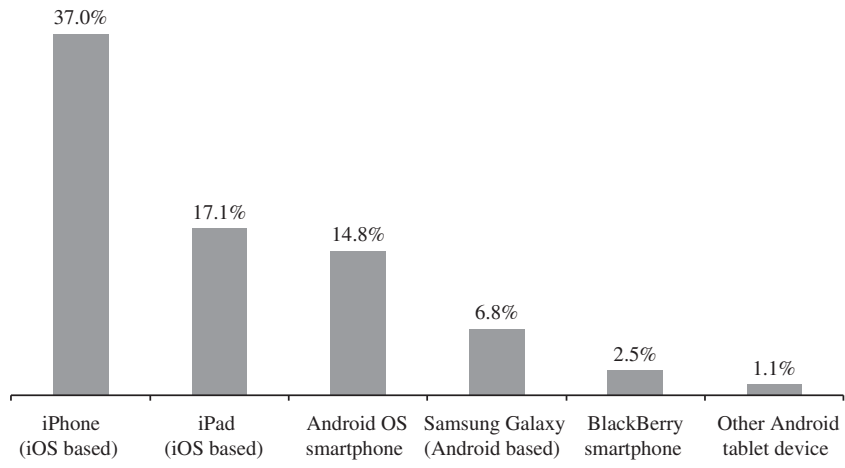

Figure 1 Mobile workers' preferred primary device choices (adapted from iPass, 2013); excerpt of iOS, Android, and BlackBerry survey data (base: global survey of 1625 mobile workers).

trend poses several challenges to Chief Information Officers (CIOs) around the world: 'What IT costs are associated with the use of mobile consumer devices?', 'How will corporate use of mobile consumer devices affect IT management?', and 'How to introduce an IT service for corporate as well as personal mobile consumer devices?'. These topics have to be addressed by John Smith, the CIO of OMEGA Group, if he decides to leverage the benefits of consumer devices like the iPhone within his company.

\section{Company background}

OMEGA Group is a multi-national company, consisting of several business units with private and business customers along with 50,000 employees distributed globally over more than 50 countries. Its business units generated revenue of more than 15 billion euro in 2011. The company has grown over the years through several mergers and acquisitions resulting in a heterogeneous company structure and culture.

OMEGA Group's centralized corporate IT department is responsible for the global IT demand. In addition, each business unit has a separate IT department acting as the interface between the central department and the business unit. For operating its IT services, the company relies on an internal IT service provider and several external providers. The highest board for IT management-related topics is the socalled 'IT Board'. Within the IT Board, the corporate IT strategy is aligned and IT-related escalations discussed. It is headed by the company's Chief Executive Officer (CEO) and complemented by the Group's CIO, the CIOs of the business units, and by the Chief Procurement Officer (CPO). On request, the IT Board is extended by certain subject matter experts. The IT Board is supported by subordinate boards with a specific IT focus such as the 'IT Infrastructure Board', 'IT Security Board', 'IT Architecture Board', and 'IT Commercial Board' (see Figure 2).

At OMEGA Group a larger share of the field force is equipped with mobile phones. In particular, Windows Mobile handhelds are deployed to support sales staff with a customized mobile application. The middle and top management use BlackBerry devices to access corporate e-mail, contact, and calendar data (so-called 'Personal Information Management' (PIM) data). In addition, a larger number of Nokia devices with no mobile data access are in circulation.

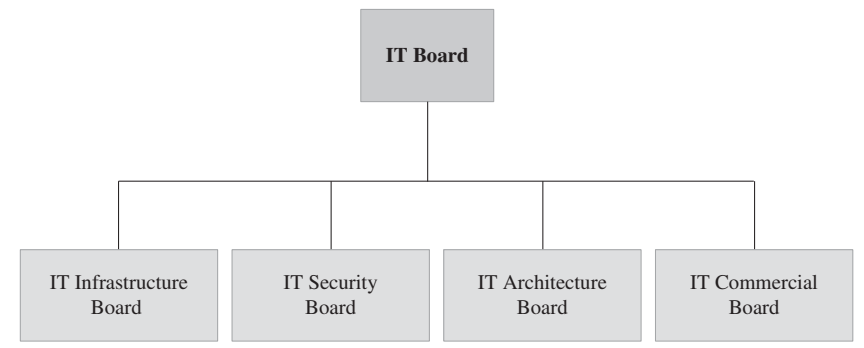

Figure 2 OMEGA Group's IT board structure.

\section{What drives consumer technology adoption}

Following his normal routine, upon arrival at OMEGA Group's headquarters, John grabs a cup of coffee at the company's coffee shop. Just next to him a group of junior and senior employees are in a lively discussion about mobile devices. As John is interested, he joins the group. The group, without noticing who is following the conversation, is discussing the mobile phones available through OMEGA Group's IT department. A young lady says, 'I think our personal phones like the iPhone or Android phones are much better than the Nokias we get from OMEGA Group. I really wish we could use these phones for work. Don't you?' A senior colleague supports her argument, 'Yes, me too! My personal iPhone is much easier to use than my corporate BlackBerry. I like its touch screen, intuitive menu and great design. It's got way more style.' Everybody is laughing. Just after they stop laughing, he adds, 'All the apps available for the iPhone would also be great for business, if we could use them. In particular, the context sensitivity provided by the integrated sensors and exploited by these apps is great. And I would only need to carry one device for personal and corporate use. Don't you think?' The lady nods her head and responds, 'You're right. But don't forget that if the IT department made iPhones available, due to the pretty high device costs, they would likely only be available to a certain management level and select employees. Sooner or later iPhones could replace the BlackBerrys and be the new status symbols.' She pauses, smiles, and continues, 'But, I would like to have one to be more productive at work and, to be honest, the image and status associated with the iPhone would motivate me. Somebody should submit a request for the introduction of iPhones to our CIO.' A colleague taps on her shoulder and whispers, 'Hmm, actually you can just ask him right now.' With a big smile on his face John says, 'Interesting discussion, I will think about it. Have a nice day.'

John leaves the group, walks down the floor and takes the elevator to the 40th floor where his office is located. Jane, his secretary, welcomes him, 'Hello John. How was your weekend?' John smiles, 'Hi Jane. I had a great and relaxing weekend. I wish I could have more weekends like the last one,' and continues, 'I just followed an interesting discussion at our coffee shop about mobile consumer devices. I got some insight that might be helpful in our discussion in the IT Board right now.' Before John could enter the IT Board meeting, Sally grabs his arm, 'Oh sorry John, could you just approve these 20 iPhone orders for a group of executives. They ask almost daily if the orders have already been sent out by procurement.' Being astonished John says, 'Don't they know that no corporate data and no e-mails will be provided with these devices? Our IT security department hasn't approved the 


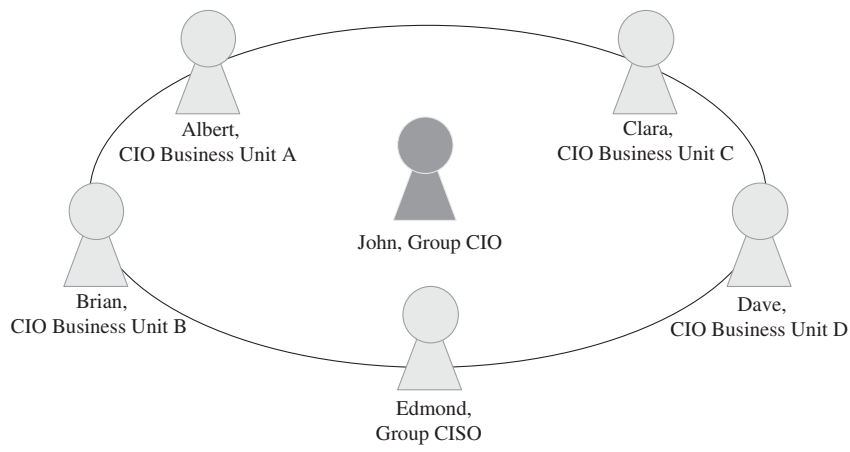

Figure 3 Participants of IT Board meeting.

access to corporate data on iPhones yet.' Sally replies, 'Yes, they do, but they are not happy about it.' Opening the door to the meeting room, John says, 'I will have to deal with that after the IT Board meeting, sorry Sally. It's a good thing we are discussing this topic in the meeting this morning. We need to clarify if and how we can benefit from these devices.'

\section{What IT governance challenges to solve}

Today the company CEO Richard Green and the CPO Sarah Miller cannot attend the IT Board meeting. Therefore it is headed by John Smith. The board meeting is complemented by the business units' CIOs Albert Austin, Brian Baldwin, Clara Cole, and Dave Dudley. This time the round of the company's IT management executives is extended to include the Group CISO (Chief Information Security Officer) Edmond Elias, who is responsible for all IT-security-related topics (see Figure 3).

As John enters the meeting the IT Board members are already awaiting his arrival. John gives a short introduction and continues, 'As some of you know, Sarah and Richard, on short notice, had to travel to London to attend a meeting with one of our key customers. So we are going to have to shift most of our agenda topics to the next meeting. I didn't cancel the meeting since we were able to have Edmond be here today to discuss with us the use of mobile consumer devices within our company. We will inform Sarah and Richard in our next meeting about the key outcome of our discussion and then align possible next steps. This topic is urgent because more and more employees, and in particular our executives, want to use such devices for business. Clara, I know that within your business unit you dug pretty much into this topic. And I know you attended this year's Mobile World Congress in Barcelona. What's your opinion on the corporate use of mobile consumer devices?'

Clara smiles and responds, 'That's not an easy question. First of all, let me start by discussing the financial aspects. John and I discussed it some months ago that iPhone devices are more expensive than our BlackBerrys, even if you compare the most expensive BlackBerry to the cheapest iPhone model. Not to mention that, we would have to introduce an IT service for the mobile access of corporate PIM data on these consumer devices, a so-called mobile PIM service. We would end up paying a service fee, just like we do for the BlackBerry. Finally we would need to do a financial model of the reoccurring mobile communication costs. Of course, we could provide
iPhones based on our existing smartphone rate plan. To be honest, I doubt that this rate plan is appropriate for consumer devices. We obviously would have a different usage pattern on mobile consumer devices like the iPhone. A resulting increase in the volume of mobile data would lead to higher IT costs unless we introduced countermeasures. I think that our employees would use the apps, which would include bandwidth-intensive streaming services. I know that we forbid any application use on our BlackBerry devices. We would have to change this if we would introduce iPhones or other mobile consumer devices. You know that, even though not officially introduced, a lot of top management executives use iPhones. One reason for their interest in these phones is the number of available apps that can be used for private or business purposes. However, it would be ridiculous to provide these devices and lock out the apps. I believe that we would benefit from these devices, but it is hard to quantify the monetary benefits we would get by investing in it. This makes it hard to make a decision on pure financial data and to justify why these devices should be introduced.'

At OMEGA Group provider subsidized iPhone costs range from 100 to 300 euro compared with 5 to 60 euro for the purchase of BlackBerry smartphones. However, nearly $100 \%$ of the employees equipped with a corporate BlackBerry are using the expensive high end model. In addition, as Clara mentioned the company would have to pay a service fee as for the BlackBerry operations. ITSP, OMEGA Group's internal IT service provider, plans to introduce a mobile PIM service for consumer devices. The targeted fee of this service, including licensing and support costs, for the first year is twice as high as for the BlackBerry PIM service, which currently is priced at 10 euro per device per month. For year two and three a monthly service fee of 5 euro is targeted for the iPhone service by ITSP. The smartphone rate plan is priced at 20 euro per month per SIM card and includes 30 megabytes (MB) of national and $10 \mathrm{MB}$ of international mobile data usage. The $30 \mathrm{MB}$ and respectively the $10 \mathrm{MB}$ can be used in a pooling scenario across all business units and devices. This means that if some use more and some use less data volume no extra costs occur - provided that the consumption stays in balance across all phones. Currently the national pool is utilized by nearly $95 \%$ and the international pool only by $50 \%$. If the data pools are exceeded, each additional $\mathrm{MB}$ will be charged. For mobile voice communications, the plan includes $400 \mathrm{~min}$ for international or national usage provided in a pooling scenario. This pool is utilized by $50 \%$.

'I see your concern,' Dave gets involved in the discussion and continues, 'However, as other mobile consumer devices, mainly Android based, are typically less expensive than the iPhone models we could extend the availability to a broader range of consumer phones. This could be one option to lower device acquisition costs. In addition, by allowing our employees to use their personal phones for corporate purposes we have another possibility to reduce the device costs. By the way, have you ever thought about the possibilities of the added business value these devices could provide? We could improve our business processes, for example, with a focused use of iPhones or iPads in the sales process.' Clara answers, 'Yes, I thought about it, but keep in mind Dave that the added value, for example through efficiency increase or employee satisfaction, is hard to quantify. Nevertheless, on the one hand, the use of personal employee devices within the company would 
save investment costs. On the other hand, you have to consider that we have to pay a service fee for each device. If a huge number of employees use this service, in particular employees that did not have a corporate phone before, our IT costs would go up. Moreover, we can't overlook that the data privacy issues have to be clarified before introducing such a service.'

Reflecting awhile on Clara's and Dave's comments, John answers, 'We definitely have to clarify this.' Clara responds, 'Yes, we should. You also have to think about further IT governance challenges we would have to face by using those devices for corporate purposes, especially the challenges that pop up by using these devices for more than PIM access. First of all, I think we can use a proxy server, placed in a separate network segment, for the backend server access, to provide the PIM data onto mobile consumer devices. But if in the midterm we want to provide more sensitive data, like ERP or CRM data, onto those devices, we will probably have to find a new IT architecture standard to make a secure core network access from these devices. One approach is to establish a certificate based VPN connection. Certificates are also required to implement a secure WLAN authentication mechanism on mobile devices. I know the certificate support the iPhone is offering is quite good, but what about other mobile consumer devices, Android or Phone 7 based? I don't think so.' Edmond interjects, 'You're right Clara,' and continues, 'Enterprise-grade certificate support is important to implement the required high level of secure authentication measures and is probably missing for many mobile consumer devices.' John kindly interrupts, 'Ok, you mentioned lots of technical details. Did I get it right? The technical limitations of the different mobile consumer devices, mainly the missing enterprise-grade support of certificate technology, would pose a problem for us since we simply cannot apply our network access standard to so many types of devices?' Nodding in agreement, Clara and Edmond simultaneously reply, 'Yes!'

Clara adds, 'Thinking one step further, how can we deploy and manage apps as a part of a shared infrastructure service for those devices? We would have to solve several issues. First of all, there are no license models offered by Apple or Google for applications within their application stores that are sufficient for corporate environments. If we would reimburse the purchase of apps for our employees, we could lose the license if the employee leaves the company. Take Apple for example, if an employee uses the iPhone with his personal Apple ID, the license is bound to this personal ID and cannot be transferred to another ID. Secondly, if we want to develop our own apps for these devices we have to deal with the heterogeneity of mobile devices and operating systems. Application development would be more complex as it has to be adapted and optimized for the different platforms. Even our corporate web applications like the intranet would need to be adjusted for mobile access. Currently application access is only optimized for Internet Explorer and not Safari. This would also increase complexity in application development. Thirdly, application life cycle management would be complicated due to the short release cycles of mobile consumer operating systems [see Figure 4]. Mobile applications, that we would develop internally or source at one of our IT service providers, have to be regularly adapted in light of continued incremental changes. In particular, if we would put our focus on more than one operating system the update complexity increases. Finally, it would be a great challenge to set up a process for the rapid introduction of mobile apps for these devices. Our internal processes and necessary alignment steps to introduce new IT services are too complex and time consuming to effectively deploy apps on short notice - especially compared to the short app development time. Moreover, in discussing this with other companies that already have integrated mobile consumer devices, it turned out to be a challenge for IT departments to not be excluded from screening and defining the needs for business applications by the business units.'

Everybody is looking at Clara and is surprised about her deep knowledge of mobile consumer technology. 'Clara you seem to know what you are talking about. I frequently use my iPhone, but to be honest I have not thought that deeply about the impact the corporate use would have for us. I would expect that this is true for all of us. Do you see any further impact?' John asks. Clara continues, 'I think that we would need a standard service, probably cloud computing based, to make corporate files, which are centrally stored within the company network, accessible on heterogeneous devices, such as laptops, smartphones, or tablets. If we wouldn't provide this kind of standard there is the risk that employees might use an unsecure consumer cloud service like Dropbox to be able to access files seamlessly on their different corporate devices.' Edmond nods and adds, 'Cloud storage services like Dropbox are not secure from a corporate perspective. We would definitely have to prevent the use of these services by providing a viable alternative. Moreover, the use of mobile consumer devices would decrease the level of IT security we can provide by pure technical measures for mobile infrastructure services, compared to the level we currently have for our BlackBerry devices.'

Not to be left out of the conversation, Brian remarks, 'I am not an expert on this topic, but I read an interesting article on mobile consumer device security. It stated that technical limitations varying between the different mobile operating systems make it hard to administrate consumer devices at an enterprise-grade security level. The article mentioned that a

\begin{tabular}{|c|c|c|c|c|c|c|}
\hline iOS: & $\begin{array}{l}\bullet 1.0 \text { (Jun. 07) } \\
\bullet 1.1 \text { (Sep. 07) }\end{array}$ & $\begin{array}{l}\bullet 2.0 \text { (Jul. 08) } \\
\bullet 2.1 \text { (Sep. 08) } \\
\bullet 2.2 \text { (Nov. 08) }\end{array}$ & $\begin{array}{l}\bullet 3.0 \text { (Jun. 09) } \\
\bullet 3.1 \text { (Sep. 09) }\end{array}$ & $\begin{array}{l}\cdot 3.2 \text { (Apr. 10) } \\
\bullet 4.0(\text { Jun. 10) } \\
\bullet 4.1 \text { (Sep. 10) } \\
\bullet 4.2(\text { Nov. 10) }\end{array}$ & $\begin{array}{l}\bullet 4.3 \text { (Mar. 11) } \\
\text { • } 5.0 \text { (Oct. 11) }\end{array}$ & $\begin{array}{l}\cdot 5.1 \text { (Mar. 12) } \\
\bullet 6.0 \text { (Sep. 12) }\end{array}$ \\
\hline Android: & & $\bullet 1.0$ (Sep. 08) & $\begin{array}{l}\bullet 1.1 \text { (Feb. 09) } \\
\bullet 1.5 \text { (Apr. 09) } \\
\bullet 1.6 \text { (Sep. 09) } \\
\bullet 2.0 \text { (Oct. 09) }\end{array}$ & $\begin{array}{l}\cdot 2.1 \text { (Jan. 10) } \\
\bullet 2.2(\text { May 10) } \\
\bullet 2.3(\text { Dec. 10) }\end{array}$ & $\begin{array}{l}\cdot 3.0 \text { (Feb. 11) } \\
\cdot 3.1 \text { (May 11) } \\
\bullet 3.2 \text { (Jul. 11) } \\
\cdot 4.0 \text { (Oct. 11) }\end{array}$ & $\begin{array}{l}\bullet 4.1 \text { (Jul. 12) } \\
\bullet 4.2 \text { (Nov. 12) }\end{array}$ \\
\hline Year: & 2007 & 2008 & 2009 & 2010 & 2011 & 2012 \\
\hline
\end{tabular}

Figure 4 Release cycles of iOS and Android operating systems according to Wikipedia (2013a, b). 


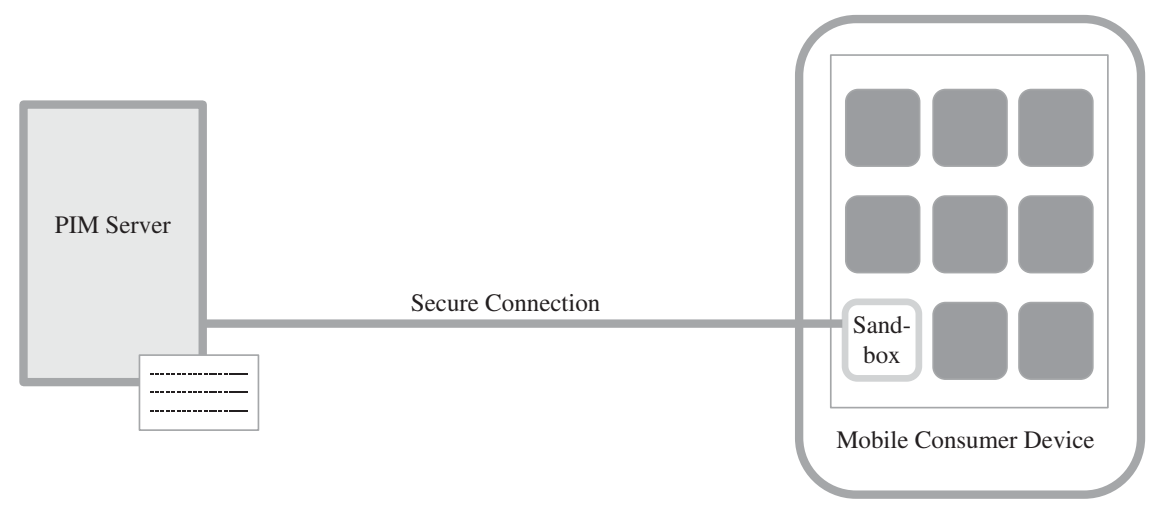

Figure 5 Simplified illustration of sandbox approach.

selective denial of application downloads is problematic. Additionally they mentioned that checks done by public application stores are not thorough enough for enterprise IT security requirements.' Edmond replies, 'You're right Brian, those issues definitely would have to be addressed.'

After a short pause John says, "Thanks everybody for shedding some light on this topic. You mentioned a bunch of issues we have to consider and clarify before we find out if we can use and operate mobile consumer devices like the iPhone within our corporate infrastructure. I guess there are still more issues we would need to tackle. What about IT support for heterogeneous mobile devices? Would it be more or less complex? Would we be able to control and dictate the mobile device portfolio used to access mobile infrastructure services? I would recommend we find external support to capture the full picture. Thanks for your contribution and the interesting comments. Nevertheless, we need to move on. Let's continue with the next point on the agenda.'

As the discussion in OMEGA Group's IT Board showed, the corporate use of mobile consumer devices and applications creates certain IT management challenges. Only for some, due to the newness of the consumerization topic, best practices do exist. Companies have implemented first measures to handle managerial issues like, for example, those related to IT support, IT security, or IT costs. To handle the device heterogeneity, IT support can be done in a self-service approach by the employee. Usage guidelines can mitigate the problem that, by pure technical measures, an enterprise-grade IT security level can hardly be provided. Increasing IT costs can be tackled by several measures, such as specific consumer smartphone rate plans or communication measures, creating awareness for a cost-efficient device usage. Thereby, usage guidelines can also help to create certain awareness and to influence employees' usage patterns. However, even having not solved all managerial challenges upfront, companies tend to integrate corporate as well as personal mobile consumer devices, in particular due to the high management interest in using these devices.

\section{How to introduce an IT service}

After attending the IT Board meeting, reflecting on the discussion about the impact of these mobile consumer devices, John thinks, 'We discussed the challenges that might arise due to the device use, but not how we could introduce these consumer devices. Perhaps Clara has some ideas.' John takes his BlackBerry, opens his address book and calls Clara, 'Hi Clara, this is John. Regarding our discussion about mobile consumer devices, I was wondering what the next steps would be if we want to start using these devices in our company. What do we need to do to set up mobile IT services for this class of devices, especially if we want to integrate personal devices?' Clara responds, 'That's not an easy question. There are not many best practices out there, especially for setting up IT services for personal mobile devices. First of all, to reduce the complexity, we should only integrate iPhones into our PIM infrastructure by setting up a mobile PIM service for those devices. iPhones are the most requested smartphones by our employees and, as you know, even more so by top management. Starting with only providing e-mail, calendar, and contacts data we could establish a mobile PIM service for personal and corporate consumer devices based on a sandbox approach.'

A so-called 'sandbox approach' is widely used to integrate personal mobile devices into corporate infrastructures. Thereby based on strong encryption mechanisms a separate container is created on the mobile device. The most widely deployed vendor solutions synchronize PIM data through an encrypted connection from the corporate backend servers into the sandbox application on the device (see Figure 5). Through the sandbox approach, both data privacy regulations for corporate use of personal devices and company IT security requirements can be considered.

John smiles, 'Impressive. How do you know all these details?' Clara answers, 'Of course I listened to many interesting presentations at the Mobile World Congress in Barcelona. I also had many conversations with vendors, service providers, and other companies. I have also been reading lots of interesting studies on the consumerization trend. The reports address topics such as the corporate use of consumer technology or employee satisfaction with the enterprise IT. If you are interested, I can send you a copy of the pdf files [see Appendix for selected report details].'

Clara pauses and continues her explanation, 'In Barcelona I also met George Brown. George is a Managing Partner at Innocon, an international consulting company, specialized on mobile devices and applications. He shared with me some of his experience about their latest projects. George said, most of his customers have a lack of know-how, mainly on the non-IT related issues of mobile consumer device integration and the set up of so-called Bring Your Own Device - abbreviated BYOD - programs, to enable employees to bring in their 
personal devices. He also sent me some presentations on this topic. As there do only a few best practices exist in this field, companies get in touch with Innocon. In particular, non-IT related requirements and questions regarding the corporate use of personal devices are coming from data privacy, legal, and tax. These questions are concerning the subsidy of private rate plans, corporate liability for personal devices, or the handling of private employee data. These questions definitely make it necesssary to align the service design for a BYOD program with human resources (HR), legal, IT security, and data privacy departments. But don't forget, especially for the European business units, the workers' council approval is important. Missing approvals of all these stakeholders can delay the roll-out of such an IT service.'

Reflecting on Clara's comments John says, 'Ok, the same lack of internal knowledge on mobile consumer devices and the corporate use of personal devices applies for us. I do not think that we have this knowledge in-house.' Clara agrees with John, 'You might be right. But there are more aspects to consider. George mentioned that there is always high personal demand for these consumer devices coming from top management. This typically creates high time pressure at his customers. Standard processes for setting up a project are thrown overboard. It is not like any other IT service introduction. To speed up the process there is typically no project budget requested and no dedicated project team assigned. Not having an official project set up complicates the alignment with internal stakeholders from HR, legal, IT security, or data privacy departments.'

John interrupts Clara, 'Ok, I see that there are specific issues in particular when using personal devices within the company, but what now?' Clara smiles and continues with her explanations, 'According to George, the high time pressure normally pushes IT departments to skip the first project phase, the strategic assessment of the mobile PIM service. Companies should initially assess the monetary impact of the service with a three year focus. Thereby projected device costs, licensing fees, support costs, mobile communication costs, and, if possible, the valued added should be addressed. In a second step, the service has to be designed. The design phase should always start with a thorough requirements analysis. George mentioned that due to the high time pressure this task is sometimes skipped or not done as detailed as it should. Instead, companies tend to quickly screen some pre-selected vendor solutions. Vendor selection is crucial, but has to be carried out based on pre-defined requirements. In particular, business unit specific requirements should be collected including international service requirements as those coming from local law. Without solid requirements analysis there is a high risk that the selected solution won't provide the specific features required by the company. George mentioned that due to time pressure, companies tend to quickly decide for certain vendors, without thorough analysis of the market and the existing solutions. In addition, according to George's experience, companies tend to skip during the design step the definition of necessary usage guidelines. This later can create a state of uncertainty for the users and operational departments about what employees are allowed to do with their corporate or personal devices. In particular in a BYOD program, clear usage guidelines are important.'

Thinking about what Clara just mentioned, John asks, 'Did George say anything about high management attention and the time pressure that influences testing and the final service implementation?' Clara waits for a moment and answers, 'Hmm, yes, he did. He mentioned that his customers normally select two solutions which are initially tested by a small group of employees in a so-called proof of concept. Of course these solutions should be selected based on pre-defined service requirements. The most convincing solution is then further evaluated in a pilot test. George pointed out that high management interest in using mobile consumer devices can lead to a large group of executives participating in the pilot test phase, less likely in the proof of concept. These employees are typically less fault-tolerant, even during test phases. To avoid major complaints, top management test users should be made aware of performance limitations during testing by implementing specific communication measures. Not to forget, according to George, a fast increase of particularly top management pilot users is problematic. Therefore, even if desired, the IT management could hardly cancel the final roll-out of this IT service. As this normally is obvious to the IT service provider, this also restricts room to finally negotiate a good price for the official service roll-out.'

Like for other IT services the testing of a mobile PIM service for consumer devices, as described by Clara, is normally done in a two-phased approach: proof of concept and pilot test. To conduct a pilot test the IT service provider builds up the necessary infrastructure at enterprise-grade standards, sets up a helpdesk, and negotiates a price per mobile client participating in the pilot.

John interrupts Clara, 'Sorry Clara, did George elaborate specifically on the effects of high time pressure for the service implementation? I am stressing this point since I expect this to be a major issue.' Clara smiles and continues, 'As a result of high time pressure, there is often no final holistic cost calculation conducted. The business case definitely should be updated based on the actual pricing figures negotiated with the IT service provider. If not, George mentioned that this sooner or later pops up, especially when device orders and mobile data costs quickly rise. If not controlled, this often leads to nervous behavior and the implementation of short-term measures. George also mentioned that one company wanted to be consistent on how it integrated the devices into its national and international business units. In the end the company had to realize that one standardized set up does not fit all business units equally well. The requirements of the different units differed too much, so that specific regulations and processes had to be aligned with the business units.'

John thanks Clara and adds, 'We definitely need external support on this topic. We have to discuss this with Richard, Sarah, and the other IT Board members.' Nodding her head Clara responds, 'Definitely. We need a consulting company, maybe George and Innocon, to structure and analyze this topic for us.'

\section{Getting going}

In the next IT Board meeting the mobile consumer device topic is again on the agenda. After discussing the outcome of the last discussions on this topic with Sarah and Richard, the board decides to invite Innocon and other selected IT management consulting firms listed on the company's preferred supplier list. The consulting companies are 
supposed to present how they could support OMEGA Group to clarify the impact the device use would have on the company's financials and for the IT management, and which steps finally would have to be taken to set up a mobile PIM service for these devices. Two weeks later the consultancies present their project approach, team, and timeline to John, Clara, and a group of representatives from the central IT department. The project approach and the team presented by George and the final project costs, as negotiated by procurement, most convinced John to assign the task to Innocon. Let's see what analysis and recommendations the team will compile!

\section{Case questions}

1. What drives employees at OMEGA Group to push for corporate use of mobile consumer devices? Please categorize and describe the drivers based on a structured approach for information technology adoption.

2. If John and the IT Board decide to introduce corporate iPhones for mobile PIM access at OMEGA Group, will the iPhone use be more costly than the current BlackBerry use? Please apply a standard cost calculation methodology that focuses on capturing all costs occurring during the life cycle of an information technology. In addition, please outline volatile cost components.

3. What IT management challenges John and the IT Board would have to face by the corporate use of mobile consumer devices? Please use a structured approach to describe and categorize in particular the IT governance challenges created for the company's IT decision makers by a device use not limited to PIM access.

4. Identify and describe the major project tasks decisive to successfully integrate corporate and personal mobile consumer devices into OMEGA Group's PIM infrastructure! Please use a widely deployed IT service management framework to structure the tasks into standard project phases.

\section{Note}

1 Names (e.g., of case company, persons, consulting firm) and in particular the presented company data in the section 'Company Background' and the financial data in the section 'What IT Governance Challenges to Solve' have been disguised for confidentiality reasons.

\section{References}

Accenture (2011). Consumer IT: The global workplace revolution has begun. Accenture Institute for High Performance, [WWW document] www.accenture. com/sitecollectiondocuments/accenture-consumerization-it-infographic.pdf (accessed 18 September 2013).

Holtsnider, B. and Jaffe, B.D. (2012). IT Manager's Handbook, 3rd edn, Burlington: Morgan Kaufman.

Ingalsbe, J.A., Shoemaker, D. and Mead, N.R. (2011). Threat Modeling the Cloud Computing, Mobile Device Toting, Consumerized Enterprise - An overview of considerations, in Proceedings of the 17th Americas Conference on Information Systems, Detroit, USA, 2011.

iPass (2013). The iPass Global Mobile Workforce Report, iPass, March 2013. Wikipedia (2013a). Android version history [WWW document] http://en. wikipedia.org/wiki/Android_version_history (accessed 27 March 2013).

Wikipedia (2013b). iOS version history [WWW document] http://en.wikipedia. org/wiki/IOS_version_history (accessed 27 March 2013).

\section{About the Authors}

Frank Weiß is a Managing Consultant with Detecon International and researcher at the Chair of Information Systems at Kassel University. He is focusing his research studies on design and effects of mobile consumer technology on corporate IT departments. Frank graduated from the University of Bamberg, where he received a diploma degree in information systems management. His research on consumerization and the corporate use of mobile consumer devices has been published, for example, in journals such as Business and Information Systems Engineering (BISE) and various international conferences such as ECIS and Wirtschaftsinformatik.

Prof. Dr. Jan Marco Leimeister is a professor at the Institute of Information Management (IWI HSG) of the University of St. Gallen (Switzerland) and is also the Chair of Information Systems at Kassel University (Germany). He runs research groups on Crowdsourcing \& Virtual Communities, Service Engineering and Collaboration Engineering and manages several publicly and industry-funded research projects. His research has been published in a broad range of journals. In addition, Jan Marco Leimeister serves on the editorial board of the European Journal of Information Systems (EJIS), is a Senior Editor of the Journal of Information Technology (JIT), and is regularly member of program committees of international conferences in the field of Information Systems. His teaching and research areas include Crowdsourcing, Virtual Communities, IT Innovation Management, Service Science, Collaboration Engineering, and IT. 


\section{APPENDIX}

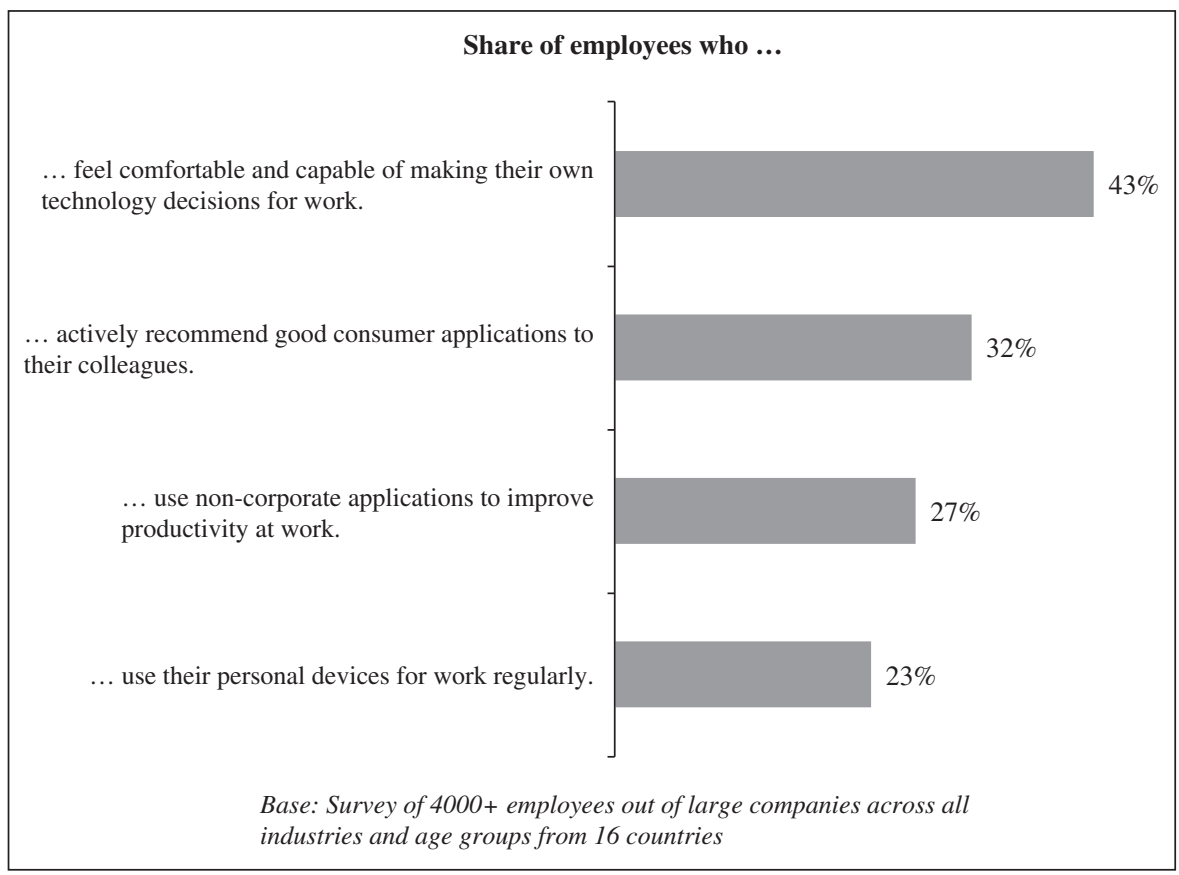

Figure A1 Statistics on use of consumer technology in companies (adapted from Accenture, 2011).

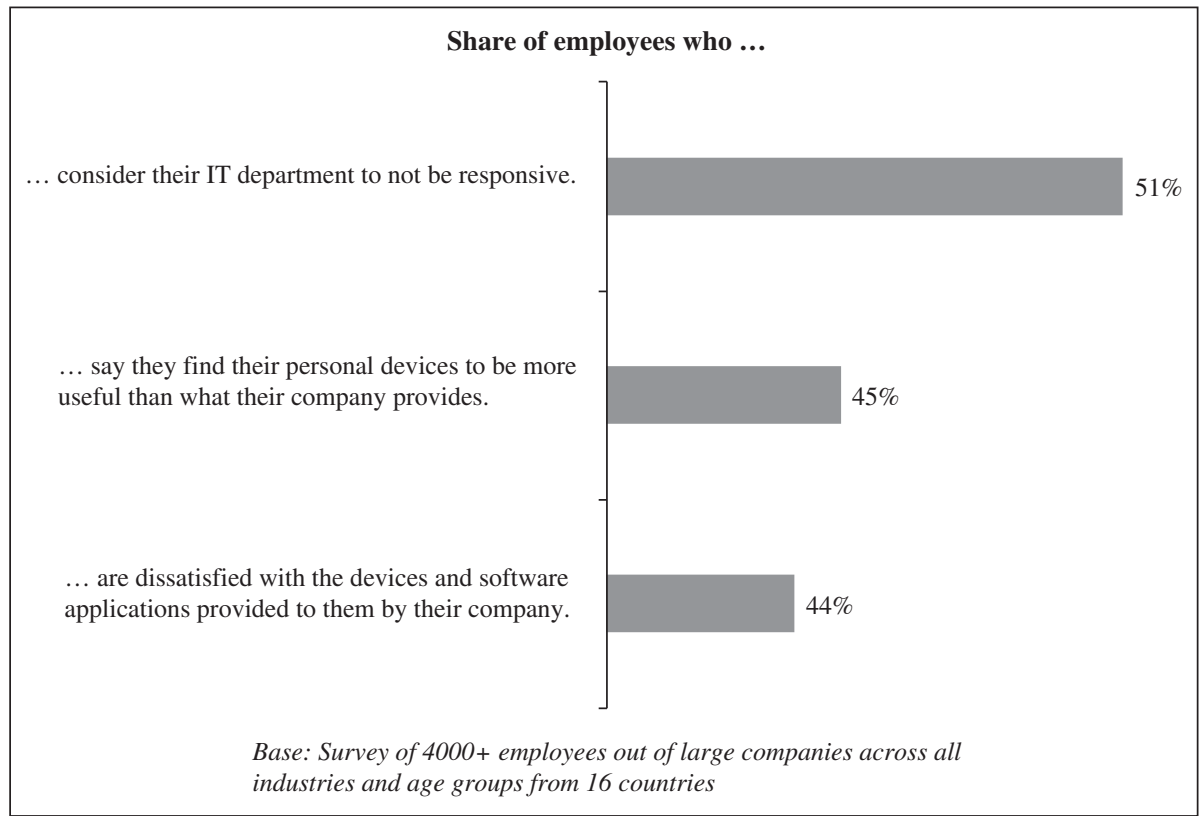

Figure A2 Statistics on satisfaction of employees with corporate IT (adapted from Accenture, 2011). 


\section{Share of executives who ...}

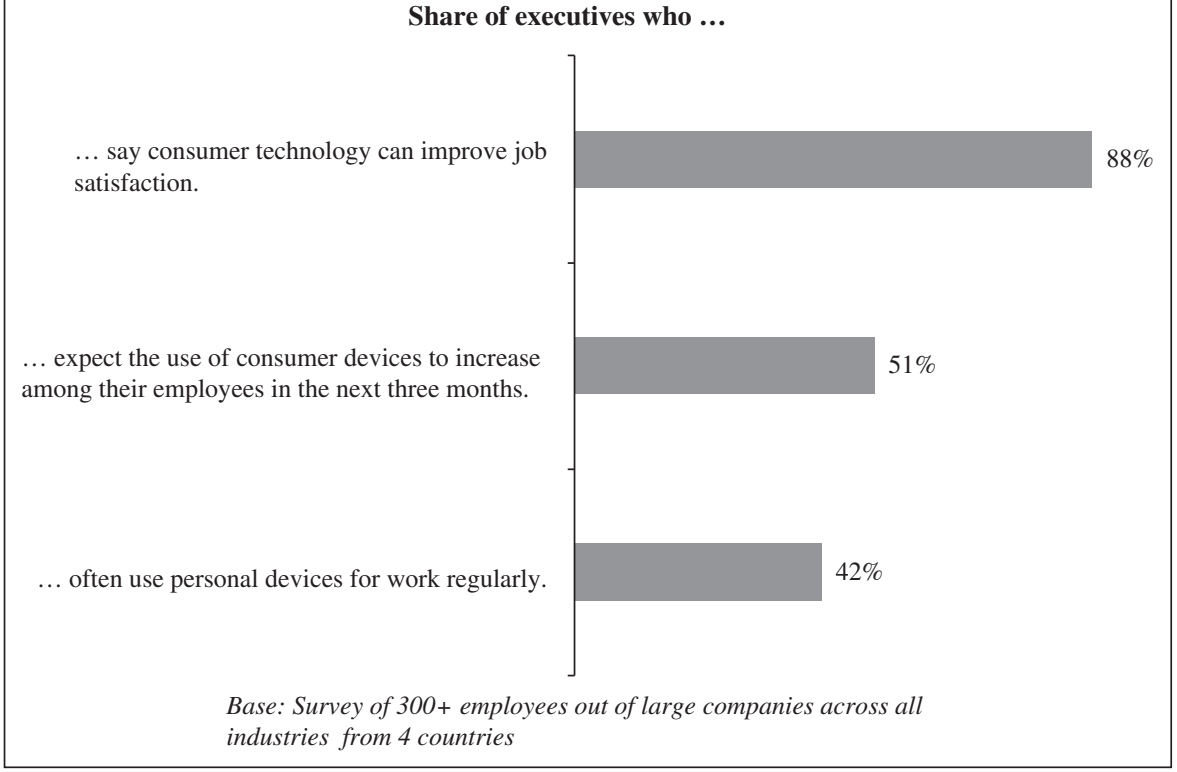

Figure A3 Statistics on top management view on consumerization (adapted from Accenture, 2011).

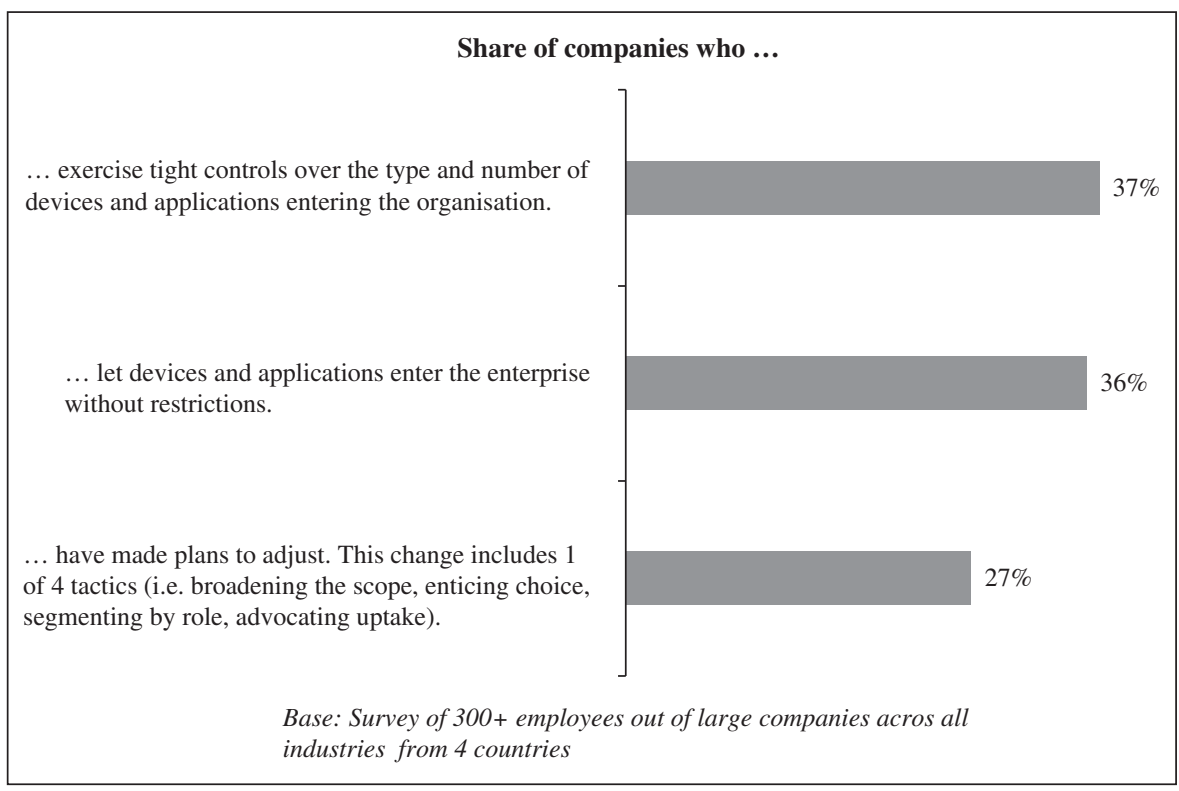

Figure A4 Statistics on managing consumer technology use in companies (adapted from Accenture, 2011). 